\title{
Editorial
}

Int Neurourol J 2012;16:1

http://dx.doi.org/10.5213/inj.2012.16.1.1

pISSN 2093-4777 · eISSN 2093-6931

\section{A New Turnaround on the Urologist's Stance over the Inflammatory Signals}

\author{
Khae Hawn Kim \\ Associate Editor \\ Department of Urology, Gachon University of Medicine and Science, Incheon, Korea \\ E-mail:kimcho99@gilhospital.com
}

Until now, the refusal by many researchers to recognize curative treatments for pelvic pain other than the individual symptomatic treatment protocol is very disappointing. Furthermore, it should be recognized that finding an optimal individual treatment protocol may require a period of trial and error. This refusal appears to have shocked people suffering from chronic pain all over the world and those pursuing the best approach and cure through primary resolution of the cause of the pain. In a review article in the March issue, Yang et al. [1] stress the primacy of the host defense mechanisms and assert that the dysregulation of innate immune response can lead to inflammatory disease pathogenesis. They also suggest new challenges for the development of novel targets and appropriate situation-dependent adjustments for the treatment of auto-inflammatory disorders including interstitial cystitis (IC). Urogenital chronic pain including prostate or bladder pain is a significant healthcare issue and is not etiology specific one. I want readers to focus on the 2 prominent clinical conditions in practice, which are chronic prostatitis/chronic pelvic pain syndrome and IC/painful bladder syndrome. There is a new turnaround on the urologist's stance over the symptomatic treatment of urologic inflammatory disease, with pursuance of the primary causes of the diseases and with priorities placed on auto-inflammation. Urologists must recognize recent advances in the regulatory mechanisms of host defense and various inflammatory diseases to optimize diagnostic and therapeutic strategies for the difficult-to-manage chronic pain that does not routinely respond to traditional treatment. Inflammasomes are multiprotein complexes responsible for the activation of caspase- 1 and caspase- 5 protease required for processing and activation of the proinflammatory cytokines interleukin (IL)-1 $\beta$ and IL-18 [2]. Moreover, NLRP3 (nucleotide binding oligomerization domain [NOD/NACHT], LRR, and PYD domains containing protein 3; also known as NALP3, cryopyrin, or CIAS1) expression is found in the urothelial layer in the bladder [3]. I think that the presence of NALP3 in epithelial cells lining the urogenital tracts allows the rapid sensing of invading pathogens, thereby triggering an innate immune response.

\section{REFERENCES}

1. Yang CS, Shin DM, Jo EK. The role of NLR-related protein 3 inflammasome in host defense and inflammatory diseases. Int Neurourol J 2012;16:2-12.

2. Martinon F, Burns K, Tschopp J. The inflammasome: a molecular platform triggering activation of inflammatory caspases and processing of proIL-beta. Mol Cell 2002;10:417-26.

3. Kummer JA, Broekhuizen R, Everett H, Agostini L, Kuijk L, Martinon F, et al. Inflammasome components NALP 1 and 3 show distinct but separate expression profiles in human tissues suggesting a site-specific role in the inflammatory response. J Histochem Cytochem 2007;55:443-52.

This is an Open Access article distributed under the terms of the Creative Commons Attribution Non-Commercial License (http://creativecommons.org/licenses/by-nc/3.0/) which permits unrestricted non-commercial use, distribution, and reproduction in any medium, provided the original work is properly cited. 